\title{
Simulation and Experimental Study of Acoustic Waves for Cleaning of Soot in Process Equipments
}

\author{
A. Shaikh ${ }^{1 *}$, N. Deshmukh $^{2}$ \\ ${ }^{1}$ Lecturer,A.R Kalsekar Polytechnic, Panvel, Navi Mumbai,India \\ ${ }^{2}$ Associate Professor, Fr. C. Rodrigues Institute of Technology, Vashi, Navi Mumbai,India \\ \{s.adnan1987@gmail.com\}
}

\begin{abstract}
In any combustion process of a fuel there will be always some unburned carbon (soot) generated and some ash carried with the stack gas stream. Soot, ash, and molten ash (slag) will accumulate at the tube banks of the heat exchangers. Some ash will even melt down at the tube surface. The final result is a layer insulating the tubes against the hot combustion gases. Soot emission from combustion devices, industrial process equipment, cause serious problems to the environment and human health. The formation of ash deposits on heat transfer surfaces has been one of the main problems encountered in industrial process equipment. Ash deposits not only lower the heat transfer rates, resulting in frequent maintenance and unscheduled shutdown.In present experimental and simulation study different length horn are used to measure sound pressure level at various distance and at different input air pressure. Then from literature equation is used to predict sound pressure level required to dislodge ash, soot and dust. Prototype is also built for demonstration.
\end{abstract}

Keywords: Acoustic Cleaner, Sound Waves, Horn Amplifiers, Sound Pressure Level

\section{Introduction}

In boilers water continuously evaporates to form steam. This increases the concentration of dissolved salts and the ionic product of the salt exceeds the solubility of product, thus precipitates are formed. If the precipitate is soft, loose and slimy it is known as sludge. If the precipitate is hard and adhering to the inner walls of the boiler it is known as scale.

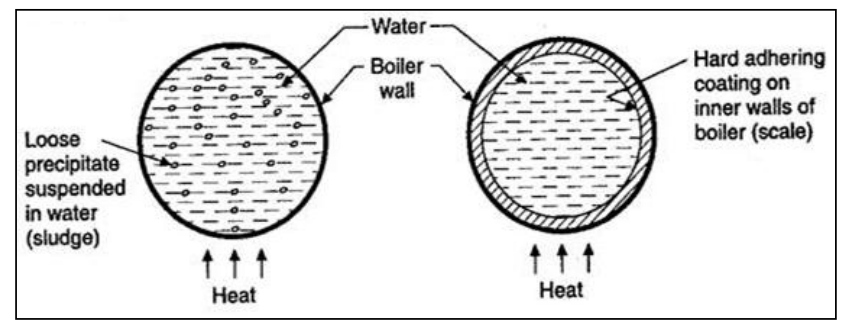

1.1 Background

Fig. 1. Scale and Sludge Formation Mechanism [19]

Fouling is generally defined as an unwanted deposition of suspended, dissolved, or chemically generated materials in process fluids on to the heat transfer surfaces. Once the scale builds up on a heat transfer surface, at least two problems occur. [9][16]

For internal cleaning, chemicals such as phosphates are added to flowing medium. Phosphate salts react with scale to form sludge. Sludge is removed during blowdown. Mechanical cleaners remove scale from tubes when the boiler is shut down. Acid cleaning also removes scale from boiler tubes and drums. The cleaning solutions consist of acids, such as hydrochloric acid, and other materials called inhibitors to reduce the attack of acid on the metal. When the cleaning cycle is complete, the boiler is flushed with alkaline and water solutions to remove any traces of acid.

B. Iyer, S. Nalbalwar and R. Pawade (Eds.)

ICCASP/ICMMD-2016. Advances in Intelligent Systems Research.

Vol. 137, Pp. 242-251.

(c) 2017. The authors - Published by Atlantis Press

This is an open access article under the CC BY-NC license (http://creativecommons.org/licens)es/by-nc/4.0/). 
Soot blowing removes soot and ash from the fire-side of boiler tubes and heat recovery equipment. Hand lances and soot blowers remove soot and ash (slag) from tube surfaces by blasting jets of air or steam, while thefurnace is on-line. Acoustic cleaning apparatus, usually built into the material-handling equipment, works by generating powerful sound waves which shake particulates loose from surfaces, reducing the need for manual cleaning.

\section{Principle of Acoustic Cleaning}

Acoustic cleaning is a non-intrusive technology designed to remove particulate buildup wherever ash, dust, powders or any other dry materials cause buildup, blockage, or thermal transfer problems [20].

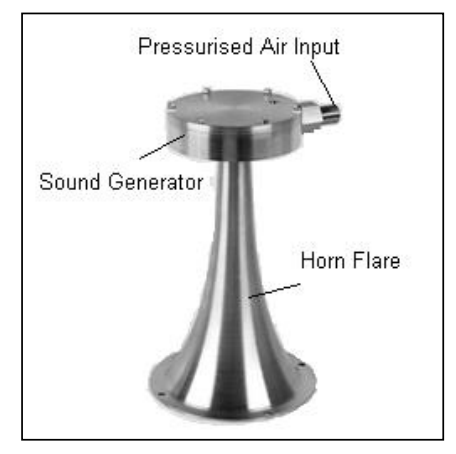

Fig. 2. Acoustic Horn [23]

The basic principle of sonic cleaning is to create a sound wave carrying an energy level exceeding the forces that tend to make particles suspended in a gas flow to adhere to each other and the surrounding surfaces, i.e. preventing a build up by breaking up the particles before they can form a hard layer.

Sonic wavelength $\lambda$ in air at $20^{\circ} \mathrm{C}$.

$$
\begin{aligned}
& \lambda=\mathrm{c} \times \mathrm{T} \\
& f=1 / T
\end{aligned}
$$

$$
\lambda=c / f
$$

Where, $c=$ Velocity of air, $344 \mathrm{~m} / \mathrm{s}$ $\mathrm{f}=$ Frequency Hertz

Sound pressure $\mathrm{P}$ can be calculated,

$$
S P L=20 \log \text { P/Pref }
$$

Where, $\mathrm{P}=$ Measured sound pressure $\mathrm{N} / \mathrm{m} 2$

Pref $=$ Reference Sound Pressure N/m2

$\mathrm{SPL}=$ Sound Pressure level $\mathrm{dB}$

$$
\mathrm{Pm}=2^{0.5} \times \mathrm{P}
$$

Where, $\quad P_{m}=$ Amplitude sound pressure $N / \mathrm{m}^{2}$

Amplitude acceleration created by sound wave is,

$$
A=20.5 \times P \times \omega / \rho c
$$

\subsection{Application of Acoustic Cleaner}

Proven applications for acoustic cleaning systems are as follows.

- Boiler Tubes/Heat Exchanger.

- Baghouse Fabric Filters/Elements. 
- Material Handling (Hoppers, Fans, Silos and Ductwork).

- EGC (Evaporative Gas Cooling) Systems.

overcut, whereas "higher-the better" quality characteristic for MRR.

\section{Theoretical Analysis of Sound Waves and Acoustic Horn}

In order to do both simulation and experimental study of acoustic horn, it is necessary to do some knowntheoretical analysis of acoustic horn, which will provide most useful parameters.

\subsection{Horn Amplifier Physics}

Fig. 6 shows the minimum geometry required to define an exponential horn.

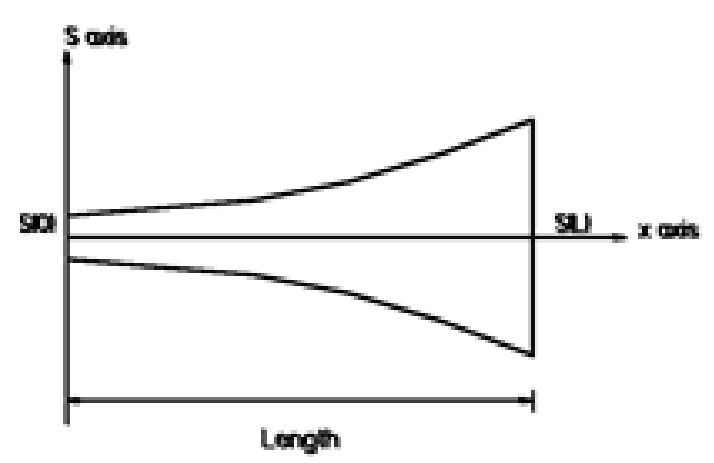

Fig. 3. Exponential Horn Geometry [20]

The exponential horn geometry is described by the following expression.

$$
\mathrm{S}(\mathrm{x})=\mathrm{SO} \mathrm{e}(\mathrm{mx})
$$

At $x=0$ and $x=L$

$$
\begin{array}{ll}
S(L)=S 0 ~ e(m L) & S(0)=S 0 \\
S(L)=S L
\end{array}
$$

From equation 9, flare constant $\mathrm{m}$ can be derived

$$
\begin{aligned}
& \mathrm{m}=\frac{\ln \frac{\mathrm{s}_{\mathrm{L}}}{\mathrm{s}_{\mathrm{O}}}}{\mathrm{L}} \\
\text { Where, } & \mathrm{m}=\text { Flare Constant }
\end{aligned}
$$

$\mathrm{SL}=$ Area of mouth

$\mathrm{SO}=$ Area of throat

$\mathrm{L}=$ Length of Horn amplifier

Classical exponential horn wave equation that can be found in most acoustics texts.

$$
\begin{aligned}
& c^{2}\left(\left(\frac{\partial}{\partial x}\left(\frac{\partial}{\partial x} \xi(x, t)\right)\right)+m\left(\frac{\partial}{\partial x} \xi(x, t)\right)\right)=\frac{\partial}{\partial t}\left(\frac{\partial}{\partial t} \xi(x, t)\right) \\
& \qquad F_{n}=\frac{m c}{4 \pi} \quad f n=\text { Frequency in } \mathrm{Hz}
\end{aligned}
$$

$\mathrm{c}=$ Speed of sound in $\mathrm{m} / \mathrm{s}$

$$
\mathrm{SL}=\frac{\left(\frac{\mathrm{c}}{2 \mathrm{f}_{\mathrm{n}}}\right)^{2}}{\pi}
$$

From Equation 12, the lower cut-off frequency of an exponential horn can be calculated given a flare constant $\mathrm{m}$. 
Theoretical Prediction of Sound Frequency of Available Horn Flares

Three acoustic horns of $250 \mathrm{~mm}, 165 \mathrm{~mm}$ and $120 \mathrm{~mm}$ of length and same throat and mouth diameter are considered. Following is the table shows the different parameters of different horn amplifier.

Table 1 Parameters of Horn amplifiers A, B and C

\begin{tabular}{|l|l|l|l|}
\hline Horn & $\begin{array}{l}\text { Throat } \\
\text { Diameter }(\mathbf{m m})\end{array}$ & $\begin{array}{l}\text { Mouth } \\
\text { Diameter }(\mathbf{m m})\end{array}$ & $\begin{array}{l}\text { Length } \\
(\mathbf{m m})\end{array}$ \\
\hline Type A & 10 & 57 & 250 \\
\hline Type B & 10 & 57 & 165 \\
\hline Type C & 10 & 57 & 120 \\
\hline
\end{tabular}

To check the cut off frequency of above horn amplifier, following steps are carried out.

For Type A

$$
\begin{aligned}
& \text { Area of Mouth }=\frac{\left(\frac{c}{2 f_{n}}\right)}{\pi} \\
& \qquad \begin{array}{l}
\text { Flare Constant } m=\frac{\ln \frac{57^{2}}{10^{2}}}{250}=0.01392 \\
\qquad f_{n}=381.25 \mathrm{~Hz}
\end{array}
\end{aligned}
$$

Repeating same procedure fn for Type B and Type C Horn can be calculated.

Table 2 Theoretical prediction of sound frequency of horn flare A,B and C

\begin{tabular}{|c|c|c|c|}
\hline Horn & Type A & Type B & Type C \\
\hline Frequency (Hz) & 381.25 & 577.90 & 794.54 \\
\hline
\end{tabular}

\section{Simulation Study of Acoustic Horn}

Methodology for simulation of acoustic amplifier is having three simple steps. Fig. 4 shows the equivalent geometry of horn amplifier with sound generator and area of sound propagation. For simulation purpose area of $2 \mathrm{~m}$ radius is considered. And an "Acoustic Module" feature of COMSOL Multiphysics $\mathbb{C}$ is used

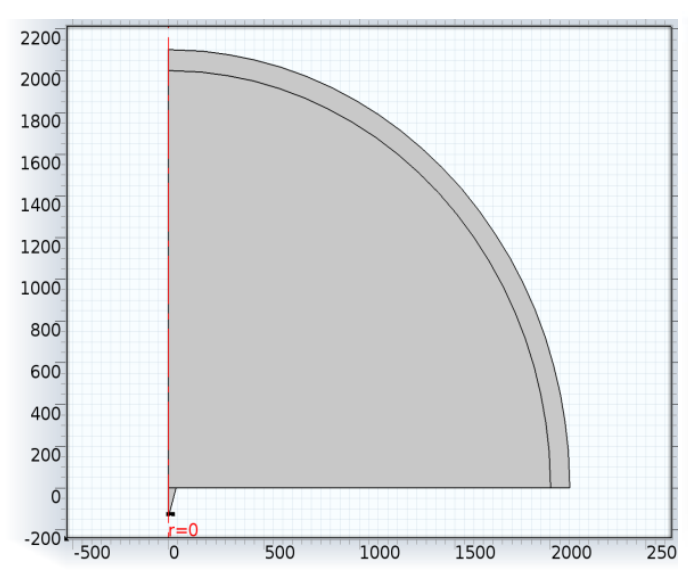

Fig. 4. Model

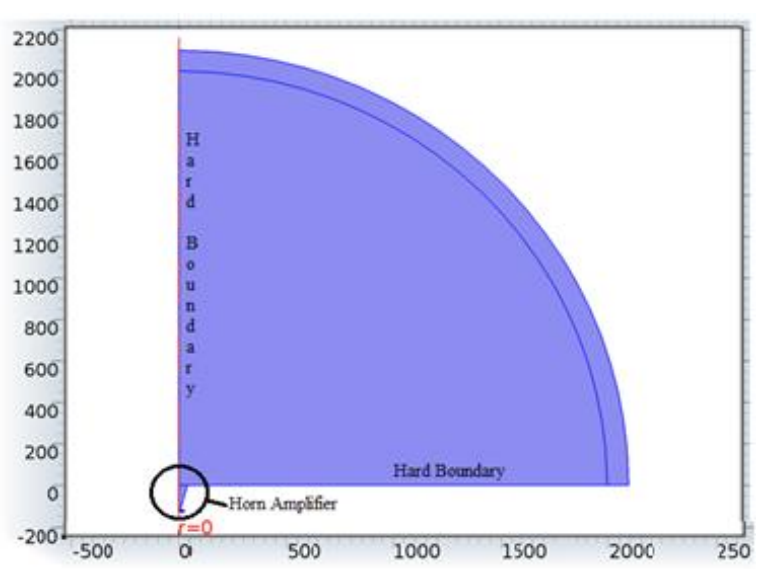

Fig. 5. Boundary Conditions

Above model is made in 2D, and shows the horn amplifier, with sound generator, and also open environment, which will be helpful in taking reading (sound pressure level) at particular location. 
It is found from literatures the movement of the diaphragm produces fluctuations in pressure, which act through a small cavity, the behavior of diaphragm is of great interest. To find out the acceleration of vibratory body following equations are used.

$$
y_{o}=\frac{3}{16} \frac{P\left(1-\vartheta^{2}\right)}{E t^{3}} R^{4}
$$

Where, $\quad$ yo $=$ Amplitude in $m$

$\vartheta=$ Poisson's Ratio

$\mathrm{E}=$ Young's Modulus in $\mathrm{N} / \mathrm{m} 2$

$\mathrm{t}=$ Thickness of Diaphragm in $\mathrm{m}$

$\mathrm{R}=$ Radius of Diaphragm in $\mathrm{m}$

This equation will give the maximum acceleration at different input pressure.

$$
a_{\text {max }}=f_{n}^{2} \times y_{o}
$$

Where,

$$
\text { amax }=\text { Maximum Acceleration in } \mathrm{m} / \mathrm{s}^{2}
$$

Above calculation will help in finding out maximum displacement and maximum acceleration. Table shows

\begin{tabular}{|c|c|c|c|c|c|c|c|c|c|}
\hline Input Pressure (bar) & 1 & 1.5 & 2 & 2.5 & 3 & 3.5 & 4 & 4.5 & 5 \\
\hline $\begin{array}{c}\text { Acceleration } \\
(\mathrm{m} / \mathrm{s} 2) \times 10^{3}\end{array}$ & 1.79 & 2.69 & 3.58 & 4.48 & 5.37 & 6.27 & 7.16 & 8.06 & $\begin{array}{c}8.95 \mathrm{E}+ \\
03\end{array}$ \\
\hline
\end{tabular}
acceleration for different input pressure.

Table 3 Acceleration of diaphragm for different input pressure

\subsection{Study Result}

Following is the simulation result for type A horn amplifier 1bar input air pressure for.

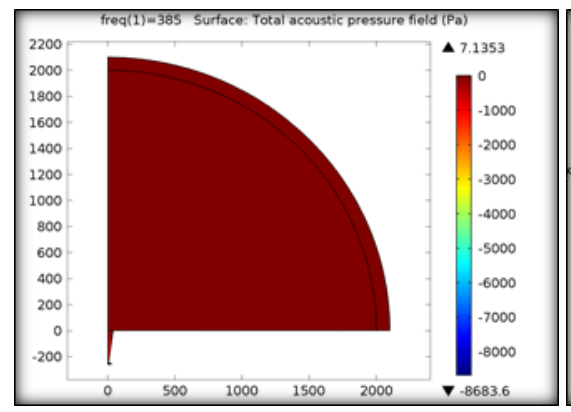

(a)

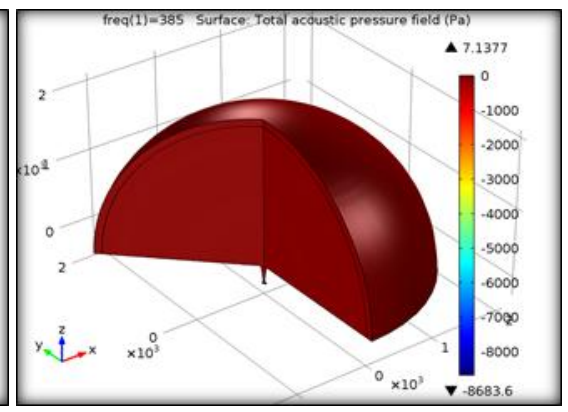

(b)

Fig. 6. Acoustic Pressure distribution.

Soundpressure generated by supplying air at the pressure of 1 bar to sound generator, and pressure distribution is plotted at 2D and 3D and shown in fig. 6(a) and fig. 7(b) respectively. From figure it can be concluded that acoustic pressure is high near to the sound generator and it get reduced as moved away from the horn. 


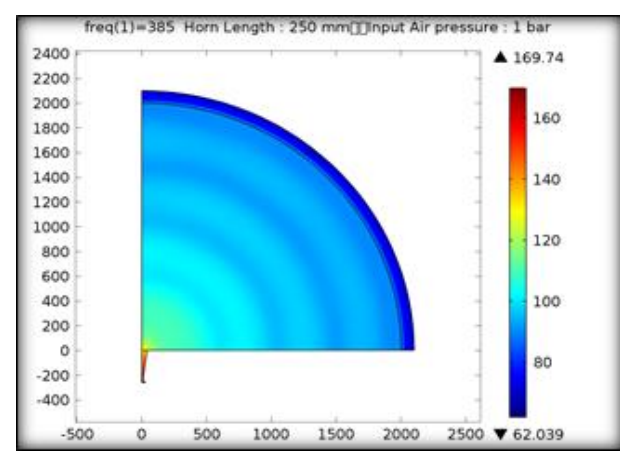

(a)

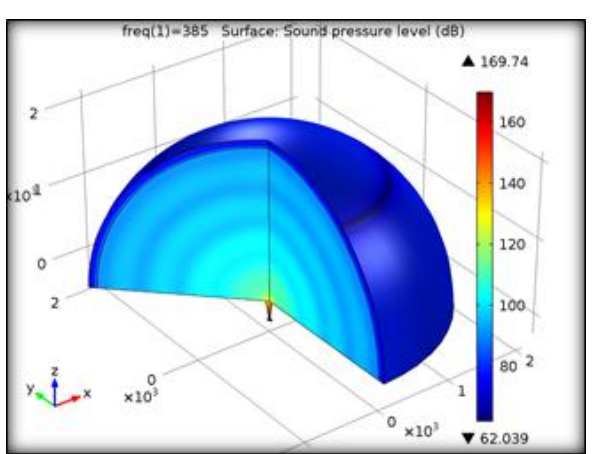

(b)

Fig. 7. Acoustic Pressure Level distribution

Sound pressure level generated by supplying air at the pressure of 1 bar to sound generator, and pressure level distribution is plotted at 2D and 3D and shown in fig. 7(a) and fig. 7(b). SPL at different position approximately at $2,1.5$ and $1 \mathrm{~m}$ are extracted and given in table 4 .

Table 4 Sound pressure level at different position from horn mouth

\begin{tabular}{|c|c|c|c|}
\hline $\mathrm{X}$ & 15.25 & 22.89 & 15.25 \\
\hline $\mathrm{Y}$ & 1996.83 & 1500.46 & 1019.36 \\
\hline SPL & 91.12 & 93.14 & 97.34 \\
\hline
\end{tabular}

Similarly simulation is done for other horn amplifiers which are given table 4.

Table 5 SPL (dB) generated by different horn flare at different air pressure

\begin{tabular}{|c|c|c|c|c|c|c|c|c|c|}
\hline \multirow[b]{2}{*}{ Distance $(\mathrm{m})$} & \multicolumn{3}{|c|}{ For Type A Horn } & \multicolumn{3}{|c|}{ For Type B Horn } & \multicolumn{3}{|c|}{ For Type C Horn } \\
\hline & 2 & 1.5 & 1 & 2 & 1.5 & 1 & 2 & 1.5 & 1 \\
\hline SPL (dB) & 91.1 & 93.1 & 97.3 & 95.5 & 99.4 & 102 & 107 & 108 & 113 \\
\hline & 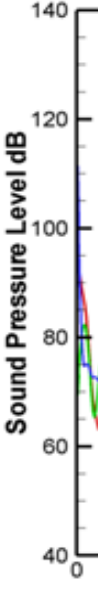 & & & $V$ & & $-T$ & ]$_{000}$ & & \\
\hline
\end{tabular}

Fig. 8. Comparative frequency spectra for horn A,B and C 


\section{Results and Discussion}

After extensive theoretical, simulation and experimental investigation data and result should be discussed to show the difference between all the methods which are adopted.

\subsection{Comparison of Sound Cut off frequency}

To determine the cut off frequency of different length horns then using Fast Fourier Transformation (FFT) tool in LabVIEWC of National Instruments.

Above graphs shows the peak at most influential sound wave frequency for different length of horn amplifier, fig. 13 shows the peak value between 850-900 Hz. Sound frequency of all type of horn amplifier (A, B and C) obtained from experiments are compared with theoretical results, which are tabulated in table 8 .

Table 6 Frequency of sound waves generated in different length horns

\begin{tabular}{|l|l|l|l|l|}
\hline $\begin{array}{l}\text { Sr. } \\
\text { No. }\end{array}$ & Technique used for determination of & \multicolumn{4}{l}{ Horn Length $\mathbf{( m m})$} & $\mathbf{2 5 0}$ \\
\hline frequency (Hz) & Theoretical & $\mathbf{1 5 0}$ & $\mathbf{1 6 5}$ & 381.25 \\
\hline & & 794.54 & 577.90 & \\
2. & NI's Data Acquisition system & & & $450-500$ \\
\hline
\end{tabular}

In the table 6 the approximate values of frequencies of sound waves for different horn length by using theoretical and experimental are compared.

\subsection{Determination of Sound Pressure Level}

Fig. 18 shows the comparative frequency spectra for all horns at a distance of $1 \mathrm{~m}$ and for 1 bar. Similarly graph is plotted for distance $1.5 \mathrm{~m}$ and $2 \mathrm{~m}$ and for input air pressure of 1.5 bar and 2 bar and results are tabulated in table 7 .

Table 7 SPL generated by different horn flare at different air pressure

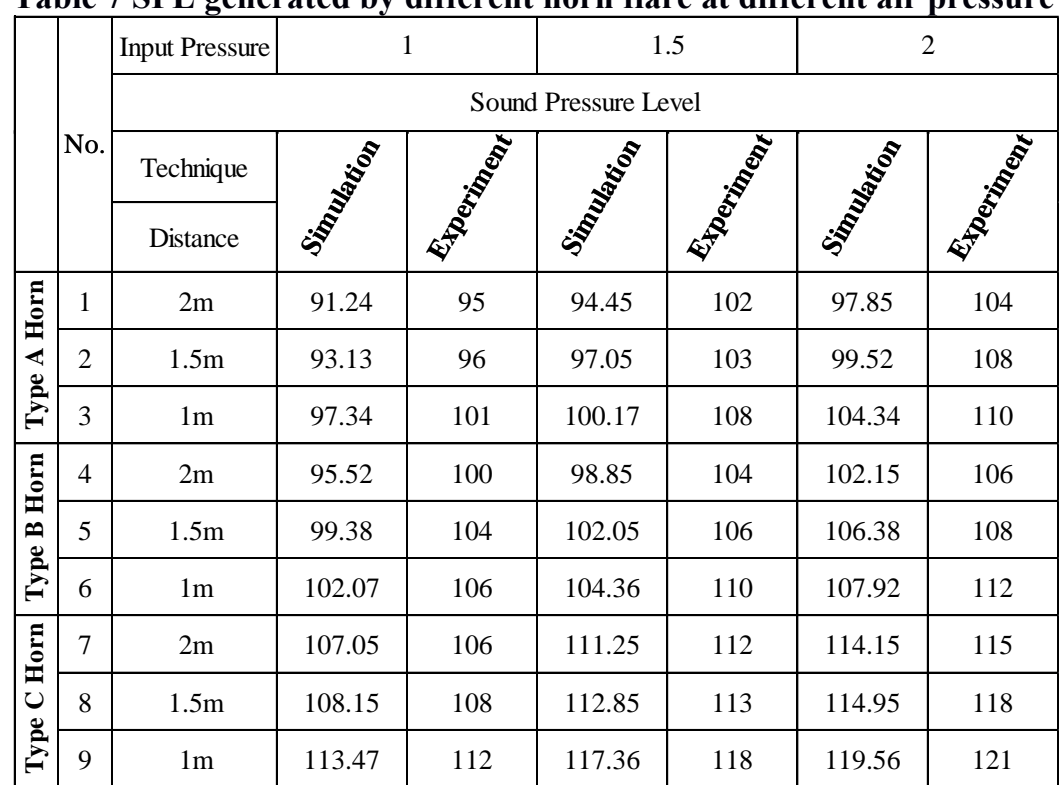

From table 7 it can be seen that for lower input air pressure sound pressure level generated is low while for higher input air pressure sound pressure level generated is higher. 


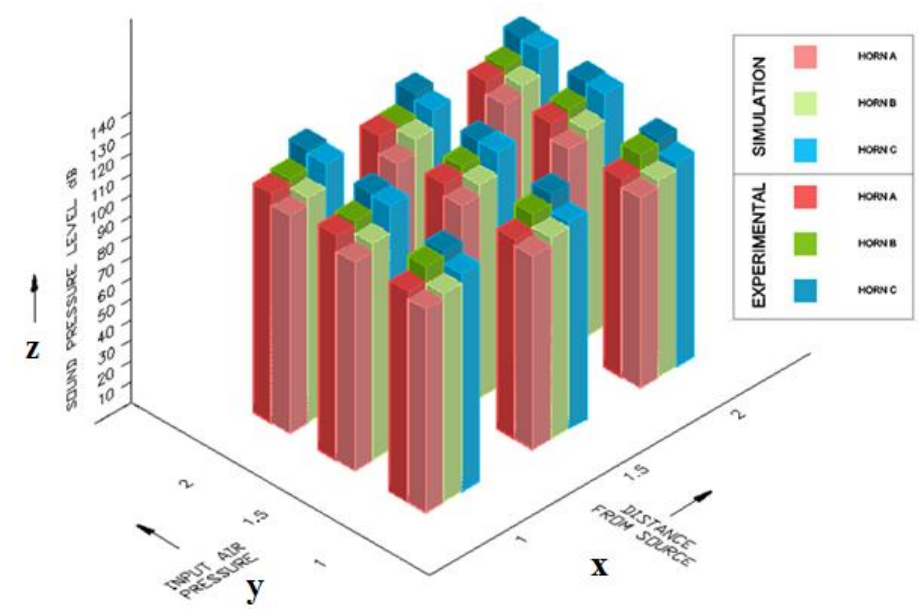

Fig. 9. Comparative Histogram for Simulation and Experimental result comparison for different type of Horn

Fig.9 show the graph which is plotted using readings from table 9. Graph shows approximate simulation and experimental results. Axis x shows the distance from sound source, axis y shows the input air pressure and axis $\mathrm{z}$ shows the sound pressure level of each horn. Type $\mathrm{C}$ horn is used at 2 bar air pressure, and it can be referred as experimental and simulation results are in good agreement.

\subsection{Requirement of Acoustic Wave for Cleaning Purpose}

As suggested by GU Yu et al [12] sound pressure required to dislodge the ash, dust and soot from any surface area,

$F=2 P \times S$

Where,

$\mathrm{F}=$ Force in $\mathrm{N}$

$\mathrm{P}=$ Sound Pressure in $\mathrm{N} / \mathrm{m}^{2}$

$\mathrm{S}=$ Fouling Area in $\mathrm{m}$

Let's consider $40 \mathrm{~N}$ force is needed to dislodge Dry Dust / Ash particulates from $1 \mathrm{~m}$ x $1 \mathrm{~m}$ square area,

From equation

$F=2 P x S$

$40=2 P \times 1$

$P=20 \mathrm{~N} / \mathrm{m}^{2}$

From equation

$$
\begin{aligned}
d B & =20 \log (\text { P/Pref }) \\
& =20 \log \left\{20 /\left[2 * 10^{-5}\right]\right. \\
& =120.00 \mathrm{~dB}
\end{aligned}
$$

Above calculation shows the approximate sound pressure required to dislodge the material from the surface. The experimental result shows that with higher length of amplifier and higher pressure more than $120 \mathrm{~dB}$ sound pressure level can be achieved. 


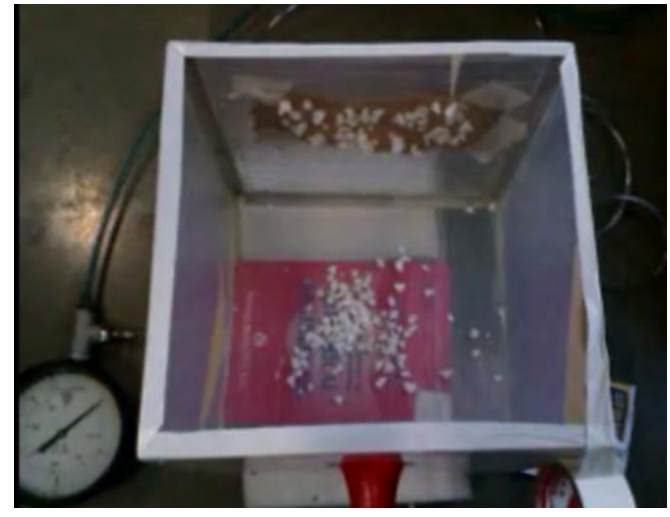

Fig. 10. a)Before producing sound waves

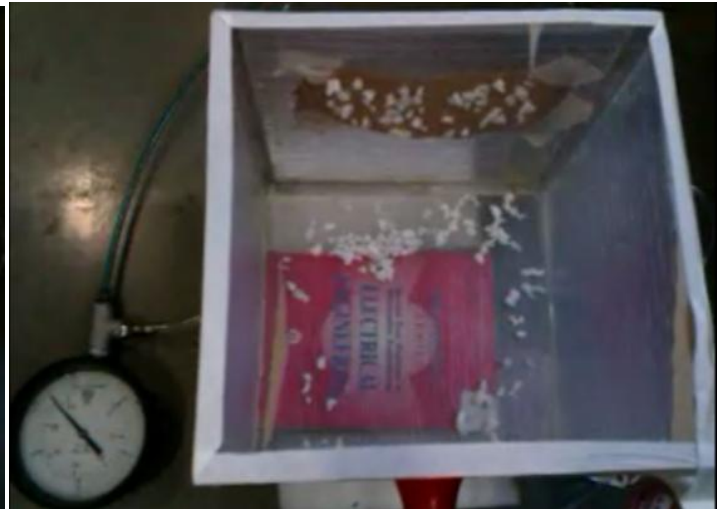

b)After producing sound waves

Fig.10 shows experimental setup to find out the sound pressure required moving or dislodging thermocole ball, prototype is made which comprises one closed chamber which will act as a closed process equipment and to show dust, ash and soot particles thermocole balls are used, and again different experiments were conducted. Initially type A horn amplifier is blown out with the input air pressure of 1 bar not produce thermocole balls to displace as shown in fig. 20. Similarly experiments for input air pressure of 1.5 to 3 bar are carried out. Fig. 15 shows that at 3.5 bar sound waves started causing displacement of thermocole ball. From experiments it has been found that lower the frequency higher will be the cleaning area. And for this purpose Type A horn amplifier is found to be suitable, which should be blown at the 4 bar pressure.

\section{Conclusions}

Sound pressure level and sound frequency prediction using theoretical and experimental method for cleaning purpose is investigated in this dissertation. Theoretical analysis is done to find out acceleration of diaphragm of sound generator for different input air pressure and effect of length of horn amplifier on sound frequency, these values then used in COMSOL Multiphysics software to predict the sound pressure level at different distance. Experiments are conducted for same type of horn amplifiers and its values then compared with theoretical and simulation results. From theoretical, simulation and experimental analysis it is found that larger will be the length of horn amplifier lesser will be the sound frequency. The same experimental technique used to see the effect of sound frequency and sound pressure level on approximately equivalent to dust and soot model. It is concluded that with lower frequency sound wave larger will be area cleaned.

\section{References}

[1]. web link: http://www.transtutors.com/homework-help/engineering-chemistry/softening-ofwater/sludge-formation.aspx

[2]. Munson, B.R., Young, D.F., Okishi, T.H., Fundamentals of Fluid Mechanics, 2nd Edition, Wiley, New York (1994).

[3]. Branch, C.A., Miiller-Steinhagen, H., "Influence of scaling on the performance of shell-and-tube heat exchangers", Heat Transfer Eng., 12, 37-45 (1991).

[4]. Kinsler and Frey, "Fundamentals of Acoustics", John Wiley and Sons, 2000, 4th edition pp. 414-416

[5]. John Borwick, "Loudspeaker and Headphone Handbook", Focal Press, 2001, Third Edition, pp.30-40

[6]. David, T. Blackstock, "Fundamentals of Physical Acoustics”, John Wiley and Sons, 2000, pp.252-267

[7]. Marshall Long, “Architectural Acoustics”, Elsevier Academic Press, 2006, 228 - 234

[8]. Lotte Buhl, Steen Drue and Leif Lind, "Field Testing of Acoustical Cleaning of Electrostatic Precipitators", in ICESP VI Conference on Air Toxics Series, Budapest, Hungary June 18-21, 1996

[9]. Tian Jing, "Applications of the Sonic Soot Cleaning Technique in Boilers", International Commission for Acoustics, Seattle 1998 
[10]. Wan Ronghui, Han Ke, Tan Ruitian, “Acoustic Horn Made Electrostatic Precipitator Collecting Plate and Hopper Clean in Zhanjiakou Power Plant”, Lianoning Zhongxin Automatic Instruments Co. Ltd.

[11]. Gary Seiffert, Barry Gibbs. "Removal of Charged Powder Deposits by High Intensity Low Frequency Sound: The Role of Inertial and Drag Forces", The thirteenth International Congress on Sound and Vibration 2006

[12]. Gu Yu, Jin Bs, Xiao G. "The Fouling Characteristics and Comparative Analysis of Cleaning Technology of SCR" in 11th International Conference on Electrostatic Precipitation, 2009 pp 624- 626

[13]. Tian Xuan Zhang, David Michael Chapin, “Acoustic Cleaning Device with variable length to compensate application temperature", Patent 20120145182, 2012

[14]. web link: http://www.accousticcleaning.com cleaning.html

[15]. web link: http://www.sonic-horns.com/prima_sonic_horns.htm

[16]. web link: http://www.primasonics.com/acoustic_cleaning.html

[17]. Harry F. Olson, “Acoustical Engineering” D.Van Nostrand Company, Inc. 1960, 2- 4 Merritt, H. E., 1971, Gear Engineering, Pitman, New York, pp. 82-83.

[18]. Guangzhong Cao (2011). “Acoustical Measurement and Fan Fault Diagnosis System Based on LabVIEW," Practical Applications and Solutions Using LabVIEW ${ }^{\mathrm{TM}}$ Software, Dr. Silviu Folea (Ed.), ISBN: 978-953-307-650-8, InTech, Available from

[19]. Cao, G.Z. and Ruan, S.C.(2002).’Design of New Instrument Based on DSP for Measuring Car's Noise Combined with Rotating Speed. Instrument Technique and Sensor"(in Chinese), No.08, pp. 11-13, ISSN 1002-1841

[20]. Martin J. King, "Horn Physics "section 5, 2008

[21]. Allan D. Pierce, “Acoustics: An Introduction to Its Physical Principles and Applications “, Acoustical Society of America (June 1989) 